\title{
DAVID HUME E KARL POPPER: RELEXÕES SOBRE INDUÇÃO E DEDUÇÃO
}

\author{
Maria Magdalena Cunha de Mendonça ${ }^{1}$ \\ Faculdade Do Isba (FSBA) \\ https://orcid.org/0000-0002-8576-7301
}

\section{RESUMO:}

Procuraremos neste artigo revisitar a compreensão do filósofo escocês, David Hume acerca da noção de causalidade, partindo dos textos Investigação acerca do Entendimento Humano, Tratado da Natureza Humana, e os Diálogos sobre a religião natural. Em seguida se apresenta uma exposição e análise do que Karl Popper denomina "problema de Hume" e a metodologia da falseabilidade de teorias científicas por ele proposta em Conhecimento Objetivo, Conjecturas e Refutações, Lógica da Pesquisa Científica.

PALAVRAS-CHAVE: Relação causal; Hábito; Crença; Falseabilidade; Verificação; Confirmação; Análise observacional.

\section{DAVID HUME AND KARL POPPER: REFLECTIONS X ON THE INDUCTION AND DEDUCTION PROBLEM.}

\begin{abstract}
:
Our proposal in this article is first to rediscover the understanding of the Scottish philosopher David Hume (1711-1776) about the causality causation concept, from the texts: Enquiry concerning Human Understanding, Treatise of Human Nature, Dialogues concerning Natural Religion. Next it is followed by the presentation and the analysis of what is named by Karl Popper "the Hume's problem" and the falsifiabilityrefutability methodology of scientific theories based on these texts : Objective Knowledge, Conjectures and Refutations, The Logic of Scientific Discovery.
\end{abstract}

KEYWORDS: Relation causal. Practice. Belief. Refutability.

\footnotetext{
${ }^{1}$ Doutora em Filosofia pela Universidade Estadual de Campinas (UNICAMP). Professora da Faculdade Do Isba (FSBA), Bahia - Brasil. E-mail: salubalena@gmail.com
} 


\section{Introdução}

O problema da indução e dedução são comuns no debate epistemológico, bem como, na área da filosofia da ciência. Debate que se apresenta longe de um consenso, embora, a centralidade dos temas seja unânime entre os interessados na construção de teorias do conhecimento.

É notória as tentativas de reelaborações e soluções ao problema da indução. Desde Bacon, chegando a Popper, a tentativa de solução é revigorada.

Levando em consideração o viés cético do projeto filosófico de Hume, importa deixar claro que comungamos da recusa de incluir o filósofo escocês no rol dos epistemólogos, como o fazem os positivistas lógicos, no manifesto de 1929, bem como não comungamos da interpretação positivista de Hume que reduz o seu pensar filosófico a um mero pensar antimetafísico. Nesta linha de pensar adotamos a perspectiva de Carlos Alberto Ribeiro de Moura, em seu texto "A critica humeana da razão" (MOURA, 1997, p. 145167), sem nos comprometer com a sua interpretação fenomenalista ou nominalista de Hume.

Buscaremos nos manter o mais fiel possível à interpretação de Richard Popkin, historiador do ceticismo, que de modo razoável, a nosso ver, recusa imputar a Hume uma deturpação do ceticismo antigo ou alético, deixando claro que é importante se levar em consideração a singularidade do viés cético de Hume na época moderna.

Segundo Popkin, antes de distorcer ou refutar o ceticismo pirrônico, o filósofo escocês aponta certos problemas implícitos na versão pirrônica ortodoxa e assim, apresenta uma leitura consistente e corrigida do pirronismo, que ao invés de expurgá-la visa fortalecê-la. Chamando Hume de "o novo Pirro Popkin" afirma:

O velho pirronista, igual aos seus oponentes racionalistas, aceitava o ponto de vista de que uma proposição deveria ser aceita, se e somente quando existiam fundamentos racionais adequados para ela. [...] Utilizando o estoque de resposta dos racionalistas para os pirronistas, Hume torna-as uma vitória dos pirronistas. (POPKIN, 1980, p.126.).

Ao seguir as duas perspectivas acima mencionadas, torna-se claro o nosso distanciamento ante alguns intérpretes que teimam em imputar a Hume um pensar fundacionalista, ao modo cartesiano. ${ }^{2}$

2 Fundacionalismo é a expressão utilizada no meio filosófico sobre a questão da fundamentação do conhecimento. Oswaldo Porchat, Danilo Marcondes, Luiz Henrique Dutra afirmam que Hume, reintroduzindo no pensar moderno as questões da fundamentação do conhecimento, afasta-se em muito do pensar pirrônico ou do ceticismo alético. 
Os historiadores da filosofia cética antiga, no entanto, recusam qualquer interpretação que aproxime Hume do pensar cético. São esses mesmos historiadores que se lançam na tarefa de estudos comparativos entre o ceticismo e o segundo Wittgenstein, o das Investigações. Essas aproximações nos aparecem, no mínimo, embaraçosas, pois, como se sabe, o autor austríaco escreveu uma obra intitulada Sobre a Certeza, e, ao contrário de Hume, jamais se intitulou como cético.

Deixando de lado a pluralidade de interpretações do filósofo escocês, iniciemos os passos da sua argumentação que antecede a abordagem acerca da relação causal, propriamente dita.

É na $2^{\mathrm{a}}$ seção, do texto da Investigação sobre o Entendimento Humano (a partir de agora, Investigação) que Hume classifica as percepções em duas espécies, que se distinguem por graus de força e vivacidade. Enquanto as idéias são pálidas, as impressões, se apresentam fortes e vivazes. Classificação essa que afirma: "o mais vívido pensamento será sempre inferior à mais obtusa das sensações". (HUME, 1999, p.23).

Hume indica que não é possível ou razoável duvidar de que há uma enorme diferença em ser afetado por uma sensação de dor ou prazer, (como por exemplo, uma dor de dente, uma atração por algo ou alguém) e o simples relembrar ou imaginar essas impressões, sensações. "Um homem tomado de um acesso de fúria é afetado de maneira muito diferente de um outro que apenas pensa nessa emoção". (HUME, 1999, p.23-24, grifos da autora).

Seguindo nessa linha de argumentação, é possível, como afirma Hume, "se fazer uma ideia de uma pessoa enamorada, mas, essa ideia jamais pode se igualar à própria situação passional, ou seja, à situação dos tumultos e agitações reais da paixão". (HUME, 1999, p.24. grifos da autora).

Desse modo, se pode compreender que o filósofo indica que, ao seu ver, o pensar em afecções passadas não se mantém na memória iguais em brilho, vivacidade instantaneidade das impressões originais. Levando-se em consideração a desproporção entre pensar e sentir, em Hume, o que se vê é a fragilidade do reflexionar-se do pensar sobre si. Logo, não há como se pensar em autoconsciência, de natureza intuitiva, em Hume. Tal é o caso das pressuposições inscritas no Cogito em Descartes.

"O pensar se limita a compor, transpor, aumentar ou diminuir o que advém das impressões ou sensações". (HUME, 1999, p.25). No entanto, embora distintas em força e vivacidade idéias e impressões se mantém intrinsecamente relacionadas, então, não há como se pensar no problema mente/corpo ou dualismo em Hume.

De fato, é no célebre princípio da cópia que o filósofo reconduz as idéias às impressões deixando claro que "ideias ou percepções são mais tênues, são cópias de impressões, ou percepções mais vívidas”. (HUME, 1999, p.26). 
$\mathrm{Na}$ abordagem do princípio da cópia, ideias se baseiam em impressões. Antes de se pensar em adoção, por parte de Hume, da teoria da representação, importa destacar no seu princípio crítico, o que se vê é a aniquilação da intuição cartesiana, pois o filósofo, de modo algum, vincula ou associa o perceber ao ver como acontece em Locke, na Introdução do seu texto Ensaio acerca do Entendimento Humano, no qual se identifica o entendimento como "o olho que nos faz ver e perceber". (LOCKE, 1988, p.7).

Ora, o perceber, em Hume, nada tem a ver com a visão de lince, destituída de qualquer opacidade ou obscuridade. Estamos longe do terreno das idéias claras e distintas das Meditações Metafísicas e do empirismo tradicional.

Situando-se na contramão da clarividência cartesiana e lockeana, Hume adverte que "embora as impressões operem com o máximo vigor, tais impressões 'representam' seu objeto de uma maneira tão vívida que quase podemos dizer que o vemos ou sentimos". (HUME, 1999, p.23). Aqui, o que se apresenta é a dissolução do elo cartesiano entre percepção e visão de ordem cognitiva.

Na percepção de uma rosa, o que se apresenta são várias, distintas e desconexas impressões, que interditam uma translúcida visão do entendimento. Aqui, se pode pensar como metáfora do perceber em Hume, como uma espécie de lusco- fusco que ocupa o lugar da clareza e nitidez. Daí a razão de se poder dizer que o empirismo cético do escocês opera em um estrato de radicalidade mais profundo do que o empirismo inglês de Locke, ainda herdeiro de Descartes.

Não há razão para se insistir em aproximar Hume do empirismo ingênuo e fundacionalista. Importa se alimentar fortes suspeitas em relação aos manuais de filosofia e as generalizações feitas entre modos de pensar tão díspares: Locke, Berkeley, Hume. Trata-se aqui de indicar na leitura de alguns historiadores da filosofia uma interpretação com não poucos equívocos, pois teimam em considerar a linha do empirismo como uma espécie de totalidade idêntica, sem levar em consideração as singularidades de abordagens sobre o conhecimento humano que nelas comparecem.

No inicio da $3^{\text {a }}$ seção da Investigação, Hume aborda o tema da associação das idéias e, aqui, já apresenta os primeiros passos da sua compreensão de causalidade e do problema da indução.

Trata-se de sublinhar que há entre idéias um elo que as conecta umas às outras. Na linha contrária do argumento cartesiano do sonho e da loucura, presente na Primeira Meditação de Descartes, Hume adverte:

[...] nossos raciocínios e conversações mais sérios. [...] Mesmo em nossos devaneios mais desenfreados e errantes - e não somente neles, mas até em nossos sonhos - descobriremos, se refletirmos, que a imaginação não correu inteiramente à solta, mas houve uma ligação entre as diferentes ideias que se 
sucederam umas às outras. (HUME, 1999, p.31.grifos da autora.).

Importante é compreender que Hume não vê a imaginação como faculdade inflexível, substancializada, mas associada às impressões. $\mathrm{Na}$ passagem a cima é fácil notar que enquanto Descartes vê loucura, associada ao patológico, o sonho à ilusão, Hume afirma que ambos ("loucura", sonho) não são destituídos da lógica própria da associação de idéias que se reconduzem às impressões.

Aqui, antes de se relacionar o desvario a algum déficit mental, se mostra que ao situá-lo no similar patamar dos raciocínios e conversas mais sérias, o que se indaga é: na lógica, particular, das associações de ideias (seja em sonho, ou devaneios como em raciocínios) onde está o eu ajuizador, substancializado, inflexível, autônomo?

No associar das idéias baseadas nas impressões desconexas, como é possível se pensar em um dito eu deliberador?

Aqui, o objetivo é de destacar que na abordagem das associações de ideias, bem como no tema da causalidade, o que se vê é Hume reafirmar a sua crítica à identidade pessoal, que comparece no Tratado da Natureza Humana. (HUME, 1989, p.251). Se na associação de ideias, na relação causal o "fundamento" são impressões, então se pode afirmar que no princípio da cópia, ideias se baseiam no campo passional. Desse modo, Hume está a fazer a crítica da noção de sujeito cognoscente, defendida por Descartes e Locke. No Tratado, ao se falar de identidade pessoal, Hume adverte, seguindo na linha do seu princípio crítico da cópia, das impressões descontínuas, se adverte:

Se uma impressão engendra a idéia do eu, esta impressão deve permanecer invariavelmente idêntica durante todo o curso de nossa existência, pois o eu (o dito eu) é levado a existir dessa forma. Ora, não há impressão constante e invariável. A dor e o prazer, as paixões, não existem todas ao mesmo tempo. Assim, não pode ser de nenhuma dessas impressões, nem de nenhuma outra que se deriva a idéia do eu, por conseqüência tal ideia não existe. (HUME, 1989, p.251-252.).

$\mathrm{Na} 4^{\mathrm{a}}$ seção da Investigação, Hume divide os objetos do conhecimento humano em dois tipos; relações de idéias e questões de fato. As relações de ideias, se referem às matemáticas em geral, às ciências da geometria, álgebra e aritmética. Ao comentar sobre a distinção que Hume traça entre esses dois modos de conhecimento, Carlos Alberto de Moura adverte:

[...] o alvo maior da classificação de Hume é a noção moderna de razão, tal como esta tinha sido formulada por Descartes. O alvo da censura, é a 'mathessis universalis' que, como se sabe, em Descartes, se apresenta como "fonte" de todos os 
conhecimentos humanos. [...] Hume, indica, com precisão, que sua preocupação é antes de tudo a de mostrar que esta estipulação da matemática como sendo o modelo do saber teórico em geral não passa de mero sonho de visionário". (MOURA, 1997, p.148.).

Hume aproxima os relatos históricos e a narrativa poética. Parece ser proposital a relação que ele apresenta entre os discursos mencionados e a sua aproximação aos relatos experimentais da ciência da época das Luzes. "As relações de fatos", assim como nos relatos históricos, poéticos, se baseiam "na experiência e na relação causal."

E qual vem a ser, segundo Hume, a função da conexão causal presente nas generalizações, implícitas nos relatos do historiador, poeta épico, ou cientista da sua época? Poder de Saber.

$\mathrm{Na}$ contramão do otimismo racionalista, expresso, por exemplo, na máxima baconiana "prever para prover", de forma explícita, Hume declara que a relação causal e as generalizações e o procedimento da indução neles implícitos "é o único conhecimento que nos capacita a controlar eventos e governar o futuro". (HUME, 1999, p.35). Trata-se aqui, mais de compreender o nexo causal como uma espécie de ferramenta, mais próximo do sentido utilitário ou prático do termo e mais distante da noção de uma descoberta miraculosa da razão humana.

$\mathrm{Na}$ afirmação acima, Hume indica o sentido forte de construção do conhecimento humano em "questões de fato" e reduz a pó, em nossas generalizações experimentais, a noção de neutralidade axiológica.

A relação causal se refere às "questões de fato" e diz respeito às generalizações que são costumeiras, e se apresentam na forma de previsões ante o modo de comportar-se do campo natural e da conduta humana. $\mathrm{Na}$ análise observacional do modo de apresentar-se de um acontecimento natural é plenamente possível, como Hume afirma, "após ter observado o sol nascer uma vez, duas vezes, ou cem vezes, ser levado a alimentar forte convicção de que o sol nascerá amanhã, o que importa é não basear a inferência no entendimento ou a razão". (HUME, 1999, p.65).

Após observar por inúmeras vezes que um jovem professor de metafísica, da cidade de Koinsberg, sai de sua residência a passeio, impreterivelmente no horário das onze horas da manhã, se é levado a inferir que o jovem professor, de modo metódico, se colocará a passear em todas as manhãs e sempre às onze horas. Nessa forma de inferir, nem se cogita a possibilidade de qualquer exceção ou mudança de comportamento do professor de metafísica, como, por exemplo, deixar de sair no horário por nós previsto, devido a um mal tempo, ou indisposição física ou mental.

$\mathrm{O}$ alvo da $4^{\mathrm{a}}$ seção da Investigação é a recusa dos raciocínios $a$ priori, como antecipações legítimas do campo da "experiência". Segundo Hume: 
Torna-se difícil afirmar que sem ter observado uma ou inúmeras vezes, uma criança, que ao consumir um pedaço de pão, logo após, se diga saciada, não é possível afirmar ser o pão um alimento mais adequado aos homens ao invés dos animais, como o leão ou tigre, por exemplo. (HUME, 1999, p.470.).

Ao descartar a possibilidade da elaboração de uma relação causal sem o auxilio da análise observacional, Hume rechaça o apriorismo nele contido: inatismo e intuicionismo.

"O mais atento exame ou escrutínio não permite à mente encontrar o efeito na suposta causa, pois o efeito é totalmente diferente da causa e não pode, consequentemente, revelar-se nela". (HUME, 1999, p.48). Aqui, já se justifica o nosso ato de colocar entre aspas o que Hume denomina como experiência, questões de fato.

A relação causal se apresenta na forma de uma inferência sobre o futuro, a partir de observações passadas que são simples generalizações. A premissa pressuposta no raciocínio experimental, como Hume adverte, é o da uniformidade dos fenômenos naturais e humanos, uma vez considerados como regidos por leis inflexíveis.

Desse modo, os raciocínios experimentais, sobretudo a ciência, conforme sublinha Hume, opera à base de previsões, que aos próprios olhos da razão lógica tornam-se uma queda no arbitrário, pois neles não é possível dissimular um pensar de natureza determinista.

Ainda na $4^{\mathrm{a}}$ seção da Investigação, comparece o princípio do possível, princípio crítico, no qual se deve considerar como plenamente plausível se cogitar o contrário de toda "questão de fato", logo, aventar o contrário de um fato não só é possível, segundo Hume, "como plenamente concebível pela razão. Ora, afirmar que o sol não nascerá amanhã não é uma proposição menos inteligível nem implica mais contradição que a afirmação que ele nascerá”. (HUME, 1999, p.44).

No texto dos Diálogos sobre a Religião Natural, o princípio do possível é retomado e o alvo ainda é pressuposição da uniformidade no modo de aparecer da esfera natural, inscrito na relação causal. Hume, de fato, rechaça o pensar determinista de natureza teológica. E, então indaga:

[...] ao abrir os olhos e contemplar o mundo tal como realmente é, ser-lhe-ia impossível identificar de imediato a causa de um evento qualquer, muito menos a causa da totalidade das coisas, ou do Universo. Se poderia dar rédea larga à imaginação e a ela se poderia fornecer uma infinidade de relatos. [...] todos igualmente possíveis. (HUME, 1993, p. 146-147).

Para Hume, leituras sobre o mundo equiparam-se, e não há razão alguma para se eleger uma leitura em detrimento de outra. Aqui se deve destacar que Hume suspende qualquer espécie de juízo definitivo. Mais 
próximo do pensar cético, mais longe da motivação fundacionalista da episteme do século XVII e XVIII, a contragosto dos epistemólogos, como Noxon, por exemplo. ${ }^{3}$

As inferências causais, que se constituem, segundo Hume, em relações de ideias reduzidas às impressões, carregam nas associações sobre "fatos" e "agir" humano, o Hábito que as guia, já que a razão não pode a ele desafiar, deter.

\begin{abstract}
Imaginemos que, se tivéssemos sido trazidos de súbito a este mundo, poderíamos ter inferido, desde o início, que uma bola de bilhar iria comunicar movimento a uma outra por meio do impulso, e que não precisaríamos ter aguardado o resultado para nos pronunciarmos com certeza acerca dele. Tal é a influência do hábito: quando ele é mais forte, não apenas encobre nossa ignorância, mas chega a ocultar a si próprio, e parece não estar presente simplesmente porque existe no mais alto grau. (HUME, 1999, p.47, grifos da autora).
\end{abstract}

Mantendo-se fiel ao princípio contrário ao determinismo, o filósofo lembra como plausível se pensar, por exemplo, "que ambas as bolas poderiam permanecer em absoluto repouso, ou ainda, a primeira bola retroceder em linha reta ou saltar para longe da segunda em qualquer direção". (HUME, 1999, p.48).

A recusa de Hume diz respeito à pressuposição teleológica da linearidade na trajetória dos eventos naturais e condutas humanas. No texto dos Diálogos sobre a religião natural, Hume deixa explícita a sua recusa ante o pensar teológico:
A conduta dos eventos ou o que se chama de plano de uma providência particular, é tão pleno de variedade e incerteza, que se supusermos que ela é ordenada imediatamente por algum ser inteligente, devemos reconhecer uma contrariedade em seus desígnios e intenções, um constante combate de impotência e leviandade. (HUME, 1993, p.139) .

Em outra passagem do mesmo texto: "Se alguém fizesse abstração de tudo o que sabe ou viu, seria em absoluto incapaz de decidir, simplesmente, a partir de suas próprias ideias, qual o cenário que o universo deveria exibir, ou de dar preferência a uma situação ou estado de coisas entre outros". (HUME, 1993, p.47).

Sem deixar de indicar a fragilidade e limitação das inferências experimentais, Hume, no texto dos Diálogos, indaga ao defensor do argumento do desígnio: "Acaso já se formaram mundo sob seus olhos, e pôde você observar com vagar o progresso completo deste fenômeno, desde

\footnotetext{
${ }^{3}$ NOXON.James. la evolución de la filosofia de Hume.Madrid: Revista do Ocidente,1974.
} 
a primeira aparição da ordem até sua consumação final?”. (HUME, 1993, p.53).

Para Hume, o enigma da relação causal não se encontra nem nos raciocínios lógicos, tampouco, nas teorias ou hipóteses anteriores à "experiência". Nas análises observacionais, próprias da ciência, parece ser, então razoável se dizer: aquilo que os olhos do entendimento não vêem $o$ hábito nos leva a enxergar: "De causas que aparecem como semelhantes esperamos efeito semelhantes". (HUME, 1999, p.56).

Atribuir semelhança como identidade não consiste em valer-se dos olhos da razão. Aqui se trata de dar um passo além da própria "experiência", logo, tal "ato" não se pode explicar por argumentos lógicos, tampouco atribuir "ato" a um suposto sujeito deliberativo ou transcendental.

Assumindo caminhar na contramão do determinismo, Hume nos fala: "por mais regular que se admita ter sido até agora o curso das coisas, isso, isoladamente, sem algum outro argumento ou inferência, não prova, que no futuro, ele continuará a sê-lo". (HUME, 1999, p.58).

O hábito se instala em nossas generalizações de modo sorrateiro, mas essas generalizações ainda escondem um outro enigma. No conhecimento dos "fatos" não há a liberdade da imaginação, pois ela (conforme o princípio da cópia exige) se reconduz ao campo das impressões.

Se o "fundamento" da "experiência', das generalizações experimentais se guardasse, de fato, na imaginação, ao cientista seria, bem mais fácil, o trabalho de desconstruir as suas fantasias, se desvencilhar das ilusões. Para Hume: "[...] a diferença entre ficção e crença localiza-se em alguma sensação ou sentimento que se anexa à segunda, mas não à primeira e que não depende da vontade nem pode ser convocado quando se queira". (HUME, 1999, p.71). Dessa afirmação também se torna ilegítimo se falar em crença como algo intencional.

Ora, o que caracteriza a base da relação causal, das previsões nela construídas, nada é senão a crença, descrita por Hume, como algo tão intenso quanto o "[...] sentir a paixão do amor ao recebermos benefícios, ou a do ódio quando deparamos com injúrias”. (HUME, 1999, p.69).

Colocar em cena amor e ódio, na descrição do crer, significa conferir ‘as impressões uma força bem mais intensa do que presente na ficção. $\mathrm{Na}$ crença, se pode com Hume indagar, há algum espaço de fato, para vontade, deliberação, intencionalidade? Tudo leva a crer que não.

O filósofo escocês não compartilha do ideal da possibilidade de poder se desvencilhar de nossas crenças: ela é um poder que opera à revelia de um suposto eu.

Mais uma vez, Hume está a indagar, na relação causal, nas inferências, generalizações, previsões, onde está o eu substancial cartesiano? Em Hume, o mito do eu, seja ele cartesiano, kantiano ou fenomenológico, se transmuta na metáfora do fluxo luxuoso e radiante das impressões: 
Nós somos apenas um feixe ou coleção de percepções diferentes, que se sucedem uns às outras com uma rapidez inconcebível, estão em um fluxo e um movimento perpétuos [...]. Nosso pensamento é ainda mais variável que nossa visão [...] não há um só poder da alma que permaneça idêntico talvez um só minuto. (HUME, 1975, p. 252-253.).

Crer, para Hume, nada mais é senão um modo de sentir, difícil de definir, e ele próprio afirma que ao se tentar "[...] definir esse sentimento depararíamos, talvez, com uma tarefa muito difícil, se não impossível". (HUME, 1999, p.71).

Ora, quem se atreveria a definir atração, simpatia, aversão, antipatia? Torna-se claro que Hume não tomou para si a tarefa de fornecer respostas ou solução ao procedimento da indução. Trata-se mais de indicar um espanto, uma indagação. Há fatos? Na "experiência" o que "ao sujeito" vem a ser dado? E o que vem a ser o dado? Ao Observar acontecimentos naturais e comportamentos humanos onde se situa um eu imparcial?

A abordagem acerca da causalidade é a prova de que, segundo Hume, a função da filosofia, de matriz cética, sobretudo, é a de manter a indagação, ao contrário da ciência:"(...) o resultado de toda a filosofia é a constatação da cegueira e debilidade humanas"(HUME,1999,p.50). É nesse ponto, que o escocês distingue a filosofia da pretensão explicativa da ciência experimental. E nas generalizações habituais do cientista experimental, do historiador ou poeta, o que se refere ao suposto sujeito? Seguindo as pegadas de Lebrun, é chegada a hora de avisar ao leitor "a leitura de Hume não produziu em Kant o efeito de um despertador, mas o de um campainha $\mathrm{e}$ alarme. [...] Kant finge ceder em tudo, porque será o único meio de não ceder em nada". (LEBRUN, 1993, p10-11).

Deixando de lado uma leitura permeada de kantismo, pode-se, de forma bem razoável, conferir a Hume o que a ele pertence: a crítica da razão humana, ao invés de aventar a idéia de que a sua abordagem da causalidade e da indução ainda é "problema" que aguarda em Kant ou no kantismo a sua solução.

Hume, nas abordagens da causalidade, conexão necessária, hábito e crença deixa explícitas a sua crítica ao sujeito, ao eu substancial ou transcendental e ao determinismo.

O cético escocês, em pleno século das Luzes, antes de Nietzsche ou Freud, indica que a "experiência" na ciência do homem nos fala menos de "fatos" do que de interpretações possíveis sobre o mundo natural e humano que nos rodeia. Scarlett Marton, em seu texto, Nietzsche- das forças cósmicas aos valores humanos, não deixa de aproximar Hume a um perspectivismo, e afirma que: 
Nietzsche, mais próximo de Hume entenderia que as verdades da metafísica não passam de um conjunto de crenças com significação puramente prática, e as leis das ciências da natureza nada mais são do que esquemas abstratos ou ficções, criados pelo hábito. Ao filósofo inglês, ainda muito deveria da crítica que faz á causalidade. E de suas dívidas, essa ele chega a reconhecer. A comentadora cita um trecho em que o próprio Nietzsche menciona de forma explícita Hume 'aqui, Hume tem razão; o hábito (mas não apenas o do indivíduo!) nos faz esperar que certo fenômeno frequentemente observado se siga a outro: nada, além disso'. (MARTON, 1990, p.193).

A intérprete de Nietzsche insiste em afirmar que Hume tenta salvar as matemáticas. Será mesmo isso o que acontece? Ao retomar a sua diferenciação entre os dois modos de conhecimento, aqui, já abordados, se pode alimentar suspeitas quanto a pertinência da afirmação inflexível da intérprete de Nietzsche. É claro que Hume não retira a matemática do campo da incerteza, tal estratagema metodológico comparece, de fato, no procedimento da dúvida metodológica de Descartes, na Primeira das suas Meditações Metafísicas. Como bem assinala Moura: "[...] ao se sublinhar exclusivamente o Hume antimetafísico, corre-se o risco de transformar o seu empirismo em um vaga apologia da experiência e ai, se perde o poder de discernir o empreendimento de Hume daquele já perseguido pelo empirismo clássico". (MOURA, 1997, p.146-147).

No espanto ante a crença que adentra nas nossas generalizações experimentais, Hume parece "O que será que será, [...] que não tem medida nem nunca terá $[\ldots]$ o que desacata a gente, que é revelia, que é feito estar doente de uma folia?". (Chico Buarque. O que será - A flor da pele-trechos escolhidos pela autora).

De qualquer forma, nos parece que retomar as abordagens de Hume sobre os temas da origem das ideias, associação das ideias, causalidade, conexão necessária, crença, aliada a questão da identidade pessoal, inevitavelmente nos leva a indagar: o que os psicólogos chamam de livrearbítrio? Ou ainda, é verdade, é mesmo possível se pensar em uma ciência do Comportamento? Será mesmo razoável se pensar ou falar de um Hume fenomenólogo? Tal estudo demandaria uma abordagem mais profunda e exaustiva daquela que aqui nos propomos.

\section{"O problema de Hume": Popper e a crítica à indução}

Logo no início da sua obra, Conhecimento Objetivo, Popper (19021994) não hesita em reivindicar, para si, o mérito de ter alcançado uma solução ao problema da indução: "julgo haver resolvido importante 
problema filosófico: o problema da indução. Devo ter chegado à solução em 1927 ou por ai. Essa solução tem sido extremamente frutífera, capacitandome a resolver bom número de outros problemas filosóficos". (POPPER, 1999, p13).

No texto Conjecturas e Refutações Popper compreende a abordagem de Hume sobre a causalidade como "a refutação da inferência indutiva", e a considera como clara e conclusiva. No entanto, é o próprio Popper quem imputa a Hume "uma explicação psicológica da indução, em termos de costume ou hábito" admitindo que essa dita análise psicológica do problema da indução, “o deixa totalmente insatisfeito". (HUME, 1982, p72).

Para Popper, a "psicologia popular" de Hume incorre em sob três pontos básicos, que ele descreve como sendo: a) o resultado típico da repetição; b) a gênese do hábito ou costume; c) a crença numa lei natural.

$\mathrm{O}$ primeiro erro que se refere às atribuições de repetições nas observações experimentais, segundo Popper, se constitui em um "sistema de expectativas, antecipações, presunções ou interesses - antes que possa existir qualquer repetição". (POPPER, 1982, p.74).

O segundo erro de Hume, segundo Popper, consiste em considerar as reproduções dos eventos naturais como resultantes do hábito. Conforme Popper, garante:

\footnotetext{
Não há razão em apostar passivamente que as repetições nos imponham suas regularidades, procuramos de modo ativo impor regularidades ao mundo. [...]. Sem nos determos em premissas, damos um salto para chegar a conclusões - que podemos precisar pôr de lado, caso as observações não as corroborem. (POPPER, 1982, p.75-76.).
}

O terceiro erro de Hume, segundo o ponto de vista de Popper, é o de assumir a noção de crença como fonte basilar das relações causais, e, desse modo, conforme garante Popper, cair no irracionalismo.

Vincular ciência à crença, aos olhos de Popper, significa "admitir a irracionalidade até mesmo do conhecimento científico, levando à conclusão de que o racionalismo é absurdo e deve ser abandonado". (POPPER, 1982, p75).

Ao se observar que o enfoque conferidos ao problema da indução em Hume e Popper são distintos, se pode falar de duas abordagens distintas acerca do mesmo problema, então se torna razoável indagar sobre a legitimidade das críticas do filósofo da ciência a Hume.

Ao recusar a noção de repetição nas observações empíricas, Popper alega uma diferença entre a reprodução de eventos naturais e o que ele denomina de expectativa. Para Popper teorias, conjecturas, antecipações são anteriores à experiência, são expectativas que se distinguem de costume, crenças, convicções. O que está sendo questionado nesse ponto é a possibilidade de se considerar uma expectativa como consequiência ou 
resultado da força do hábito. De fato, Popper advoga que não se trata de meras atribuições de reprodução de evento são, para ele, hipóteses que antecedem a experiência. Segundo Popper, elas são inatas. "O que propus foi recusar essa teoria de Hume, explicando a repetição (para nós) como consequência da nossa inclinação pelas próprias repetições". (POPPER, 1982, p.75).

Segundo reza cartilha do método da falseabilidade, falsear um sistema ou testá-lo significa adotar o método de inferência dedutiva. Uma lei científica, enquanto um enunciado universal, não é refutada, pois segundo Popper, se trata da expressão de uniformidade e da regularidade existentes, garante ele, no campo natural. Tais pressuposições, não são, na verdade, em momento algum, colocado em xeque por Popper.

Associar a ciência e a convicção ou crença, aos olhos de Popper, significa minimizar o conteúdo cognitivo do conhecimento científico. Desse modo, a abordagem de Hume acerca da causalidade e o procedimento indutivo apresentam consequiências, que o racionalismo crítico de Popper, com boas razões, considera indesejáveis para a própria filosofia da ciência.

É verdade que Popper comete uma extrapolação ao reduzir a abordagem de Hume sobre a indução, a uma simples 'psicologia popular'. Tudo leva a crer que Popper não compreendeu bem o caráter crítico do princípio da cópia em Hume, cuja consequência é a de reconduzir ideias às impressões que, de forma alguma equivale a endossar o psicologismo.

Parece mesmo uma grande extrapolação se atribuir um psicologismo à compreensão humeana de hábito ou crença, ao se notar que, segundo o filósofo, se trata mais de impressões do que ideias pálidas e sem vivacidade. Como já mencionamos, é no campo passional das impressões desconexas que não há lugar para se falar em interioridade reflexiva. Hume está a retirar do costume e da crença, o pressuposto ato consciente e deliberativo, aos olhos do racionalismo.

Aliás, é o próprio Popper quem nos dá pistas sobre a razão do seu descontentamento com a abordagem de Hume: "Considero a refutação da inferência indutiva de Hume clara e conclusiva. Mas sua explicação psicológica da indução em termos de costume ou hábito me deixa totalmente insatisfeito". (POPPER, 1982, p.72).

Afirmar em Hume uma "refutação da indução" parece, de fato, uma interpretação externa aos seus textos, e, de qualquer forma, importa notar que o método da falseabilidade de Popper apresenta interesses bem distintos do projeto filosófico de Hume.

O método da falseabilidade tem como preocupação maior a demarcação que objetiva distinguir ciência de outros ramos do conhecimento. É Popper quem diz: "falseabilidade de um sistema deve ser tomada como critério de demarcação". (POPPER, 1972, p.42).

O que Popper com o seu método dedutivo deseja, na verdade, é distinguir sistemas e teorias científicas de sistemas filosóficos e metafísicos. 
Segundo ele, é possível traçar uma fronteira entre a teoria da relatividade de Einstein, considerando-a científica e a psicanálise e o marxismo como discursos alheios ao campo da ciência. A preferência da teoria da relatividade não se mostra tão problemática em relação ao ideal ante a possibilidade e sentido da demarcação (com o critério da falseabilidade) entre as diversas formas de saber. Aqui o viés epistemológico de Popper transparece e o distancia de Hume.

O critério da demarcação é o método dedutivo da falseabilidade, que é tão somente um modo de testar, falsear um sistema empírico, sob a forma de inferência dedutiva. As regras do método dedutivo são convencionais. Desse modo, o aceitar ou recusar as regras convencionais irá depender da aplicabilidade do critério de demarcação. (POPPER, 1972, p.57)

Teorias ou leis não são verificadas empiricamente, pois tais enunciados universais, aos olhos de Popper, são indispensáveis à ciência. "[...] não exijo que todo enunciado científico tenha sido efetivamente submetido teste antes de merecer aceitação. Quero apenas que todo enunciado científico se mostra (em sua forma lógica) capaz de ser submetido a teste". (POPPER, 1972, p.50).

Enunciados universais, segundo Popper, antecipam a experiência e a ultrapassam, mas jamais são destituídos de valor cognitivo. Na verdade é a adoção do inatismo e de raciocínios a priori o que faz Popper atribuir a Hume um problema.

Popper, no seu método da falseabilidade, afirma que hipóteses, teorias devem se submeter a testes rígidos, e ao passarem por eles, as teorias se apresentam como válidas de modo temporário até o surgimento de outra que se apresente mais forte aos testes. Nessa afirmação, Popper indica o caráter provisório da validade de uma teoria científica e a sua compreensão de conhecimento científico, enquanto processo evolutivo e cumulativo do saber humano.

Segundo Popper, a refutabilidade de uma teoria sempre pode ser provada (por meio da lógica dedutiva), no entanto, a sua veracidade absoluta não é tarefa realizável.

De fato, Popper apresenta uma compreensão de conhecimento como produção humana, mas que obedece a um processo evolutivo e se refere ao homem, enquanto indivíduo, sujeito, agente do saber. Ante a compreensão do conhecimento enquanto processo ascensional, então há razão de se falar em teorias mais fortes em relação a outras. Para Popper há no campo científico saltos qualitativos.

No contraponto da abordagem de Hume sobre a causalidade e o procedimento da indução e o método dedutivo da falseabilidade, em Popper, na verdade, se apresentam distintos modos de abordagem do problema da indução, e, sobretudo, singulares formas de compreensão do conhecimento e da ciência, bem como da sua função. 
Necessário se torna, então, mesmo de forma breve, indicar as particularidades na compreensão popperiana da filosofia da ciência, a fim de destacar as fragilidades de uma leitura que compreende Popper como um filósofo mais que um filósofo da ciência um epistemólogo, de linhagem kantiana.

É necessário, se compreender que os interesses epistemológicos e lógicos de Popper não são, de forma alguma, similares à motivação da abordagem de Hume sobre a causalidade, indução.

Para Hume, a noção de verdade é de pouquíssima valia no debate filosófico, que tem por característica maior um diálogo, no qual a indagação se faz presente e justamente nesse ponto que a filosofia difere da ciência em suas tentativas explicativas. "Cada solução dá continuamente lugar a uma nova questão tão difícil quanto à anterior, e leva-nos cada vez mais longe em nossas investigações”. (HUME, 1999, p.51)

Se, para Popper, há teorias científicas, e teorias filosóficas e metafísicas, na contraposição ao pensar de Hume, ele identifica filosofia e metafísica. E ciência e filosofia, compreendidas como teorias, então, possuem valor cognitivo. Segundo Popper, cabe à filosofia elucidar problemas da linguagem científica, assim a filosofia torna-se a lógica da investigação científica que tem função explicativa. Já na formulação da pergunta, Popper deixa transparecer a função explicativa da filosofia: "Quando pode uma teoria ser classificada como científica? ou Existe um critério para classificar uma teoria como cientifica?". (POPPER, 1982, p.63).

Para Hume, a verdadeira filosofia, de natureza fácil, que se distingue da difícil e abstrusa, e tem como características o enfrentar problemas, indagações e não tentar subtrair a radicalidade da indagação em pretensiosas soluções.

O problema da análise observacional e da experiência, a nosso ver, só encontrará uma abordagem que irá operar num estrato de radicalidade tão profundo quanto o de David Hume, em Thomas Kuhn, pois ele recusará a compreensão popperiana da história da ciência como um processo linear e evolutivo, e com a sua noção de paradigma ou modelos aceitos pela comunidade científica, de modo similar à Hume, irá reduzir a pó a noção de neutralidade axiológica na ciência.

Tal estudo aqui não comportaria, pois nos incumbimos da tarefa de averiguar o problema da indução e dedução, restringindo-o ao pensar de Hume e Popper, a fim de destacar uma distinção bem forte entre postura cética e sua positividade em Hume em contraposição ao racionalismo crítico que Popper endossa. 


\section{Referências bibliogáficas}

DUTRA, Luiz Henrique de Araujo. A demarcação entre ciência $e$ Metafísica. A crítica de Popper ao positivismo lógico. Campinas: Unicamp, 1990. Dissertação (Mestrado em Filosofia) - Programa de Pós-Graduação em Filosofia, Universidade Estadual de Campinas (UNICAMP), Campinas, 1990.

HUME, David. A treatise of human nature. Oxford: Clarendon Press, 1975. HUME, David. Dialogues concerning natural religion. Oxford: Oxford University Press, 1993.

HUME, David. Enquiries concerning human unsderstanding. Oxford: Clarendon Press, 1989.

HUME, David. Investigação sobre o entendimento humano. São Paulo: Unesp, 1999.

LEBRUN, Gerard. Sobre Kant. São Paulo: Iluminuras, 2001.

LOCKE. John. Ensaio acerca do entendimento humano. São Paulo: Nova cultural, 1988.

MARTON, Scarlett. Nietzsche: das forças Cósmicas aos valores humanos. São Paulo: Brasiliense, 1990.

MENDONÇA, Maria Magdalena Cunha de. O problema do eu no ceticismo de David Hume. Aracaju: Fundação Oviêdo Teixeira, 2003.

MENDONÇA, MARIA Magdalena Cunha de. Dialética e contingência no ceticismo de David Hume. Campinas: Unicamp, 2007. Tese (Doutorado em Filosofia) - Programa de Pós-Graduação em Filosofia, Universidade Estadual de Campinas (UNICAMP), Campinas, 2007.

MOURA, Carlos Alberto Ribeiro de. Crítica humeana da razão. Manuscrito, vol XX,n.2.p.145-167,1997.

NOXON, James. La evolución de la filosofia de Hume. Madrid; Ed. Revista de Ocidente, 1974.

POPPER, Karl. Conjecturas e Refutações. Brasília: UNB, 1982.

POPPER, Karl. Lógica da pesquisa científica. São Paulo: Cultrix, 1972.

POPPER,Karl. Conhecimento Objetivo: uma abordagem evolucionária. Belo Horizonte: Itatiaia, 1999.

POPKIN, Richard. the history of Scepticism from Erasmus to Spinooza.London:University of CaliforniaPress, 1979. 